\title{
SONETO COMO VARIAÇÃO FIXA FORMAL
}

\section{Sonnet as variation fixed formal}

\author{
Jamesson Buarque \\ UFG \\ jamessonbuarque@gmail.com
}

\begin{abstract}
RESUMO: Este artigo tem como tese o princípio de que o soneto é uma forma fixa porque variável. Esse princípio corresponde ao fundamento da variedade na fixidez como "igualdade na quantidade" (aequalitas numerosa). Para demonstrar a validade da proposta, aborda-se o soneto desde suas origens, a partir de Giacomo da Lentini, até a poesia de modernistas brasileiros (Manuel Bandeira, Carlos Drummond de Andrade e Vinícius de Moraes), passando-se pelo parnasiano Olavo Bilac. A análise investiga a validade do princípio de "igualdade na quantidade" a respeito do soneto atender a um molde, a uma versificação, a uma estrofação, a um esquema de rimas, a um ritmo e sua tonalidade. Para tanto, debate-se sobre a formação do sujeito e sua intervenção na poesia ocidental do século XIII ao XX, distinguindo-se sujeito centrado (anterior a meados do século XVIII) e sujeito autocentrado (posterior). Observa-se que o soneto apresenta um mínimo formal a respeito dos catorze versos em uma progressão textual lógico-discursiva que atende a: apresentação, desenvolvimento e desfecho. Como esse mínimo formal apenas existe in abstracto, o soneto tanto varia que chega a ser desrealizado, de suas origens a meados do século XX.
\end{abstract}

Palavras-chave: Soneto. Forma fixa. "Igualdade na quantidade". Sujeito centrado. Sujeito autocentrado.

\begin{abstract}
This article argues about the sonnet as a fixed form because it is variable. This corresponds to the variety in the fixity as "equal in amount" (aequalitas numerosa). To prove this, it is considered the sonnet from its origins, by Giacomo da Lentini, to the poetry of Brazilian modernists (Manuel Bandeira, Carlos Drummond de Andrade and Vinicius de Moraes), passing by the Parnassian poet Olavo Bilac. The analysis investigates the "equal in amount" considering template, versification, stanzas, rhyme, rhythm and tonality. To this end, lectures up on the formation of the subject and its intervention in the western poetry of the thirteenth century to the twentieth, distinguishing centered subject (prior to the mid-eighteenth century) and self-centered subject (later). It infers that the sonnet has a formal minimum around fourteen verses in a logical-discursive textual progression serving: proposition, development and closing. It is observed that this minimum exists only in abstract, because the sonnet varies so much that it's undone, from its origins to the mid-twentieth century.
\end{abstract}

Keywords: Sonnet. Fixed form. "Equal in amount”. Centered subject. Self-centered subject. 
Desde o surgimento, no Duecento italiano ${ }^{7}$ (CAMPOS, 1978; LIMA, 2007; BURT, 2011), até a atualidade, o soneto é um gênero poético nucleado em torno de catorze versos de tonalidade ordenada quantitativa e qualitativamente (conforme o idioma) de maneira simultânea ou sucessiva, com variedade estrófica binária e ternária (sendo, a rigor, mais comum o quarteto e o terceto - conforme seu molde de origem, o italiano), e que trata de temas diversos (p. ex.: o amor platônico, em Petrarca; o desconcerto do mundo, em Camões; a visão de mundo metafísica aristotélica, em Hopkins), ainda que em torno de quinhentos anos o amor tenha sido seu tema quase que exclusivo. De imediato, diferentemente do que o simplismo didático costuma pregar, não se trata de um poema estrofado em dois quartetos e dois tercetos, logo, não se trata de um molde inexoravelmente rígido. É verdade que o tópico de discussão que propriamente pode lidar com o soneto como uma insígnia (de gênero, de categoria ou outra) da poesia diz respeito a sua forma, jamais ao assunto, ao tema ou a outro tópico. Embora isso, flagra-se, desde o século XIII, tal variedade formal que é possível distinguir uma diversidade de tipos de soneto a ponto de causar espécie - p. ex.: o soneto francês distingue-se do soneto italiano (ou petrarquiano) pelo esquema de rima dos tercetos: CDC/DCD neste (à maneira da terça rima) e $\mathrm{CCD} / \mathrm{EDE}$ naquele, ainda que isso apresente outras variações, pois há sonetos italianos com tercetos em $\mathrm{CDE} / \mathrm{CDE}$, e $\mathrm{CDC} / \mathrm{CDC}$; outro exemplo diz respeito à métrica: dentre as línguas latinas, distingue-se a recorrência do hendecassílabo no soneto em italiano e em espanhol, do alexandrino no soneto em francês e do

\footnotetext{
${ }^{7}$ As informações de base histórica e tipológica sobre o soneto dizem respeito a tais autores. Isso é informado para evitar notificações repetidas.
} 
decassílabo no soneto em português, além do que, no interior dessas medidas, há, p. ex., o decassílabo sáfico, o heroico, o de arte maior ${ }^{8}$ etc.

Somente porque variável o soneto pode ser considerado uma forma fixa. Observe-se: em uma amostragem mínima (de três a cinco poemas), se houver distinção total (tanto de forma quanto de tema, e até outra), não se pode deixar de considerar que há no corpus em análise uma forma fixa. Mais objetivamente e sob exemplo, o gazel ou gazal é uma forma fixa de origem árabe (advinda do tempo de domínio mulçumano na península ibérica). O gazel é composto de dísticos (estrofes de dois versos) sob um esquema de rima emparelhado no primeiro dístico (AA); e interpolado, tomando-se em conjunto o segundo (BA) e o terceiro dístico $(\mathrm{AB})$. Isso forma dois esquemas binários: um de rima $\mathrm{e}$ outro de estrofe, que pode variar as rimas se o gazel se alonga, produzindo $\mathrm{CC} / \mathrm{DC} / \mathrm{CD}$ e assim sucessivamente. Quanto à temática, um gazel apresenta conteúdo amoroso ou místico, senão ambos. À parte isso, um gazel poderá ter apenas três estrofes, mas também seis, nove, doze ou mais (PAGLIARO; BAUSANI, 1980). Novamente: a forma é fixa porque variável. Qualquer amostragem de poemas que apresente esse esquema levará o analista a considerar que todos são gazéis, por mais que se apresentem variações internas (seja de métrica, de prosódia e mesmo do próprio esquema de rima) $)^{9}$. Se alguém, como poeta, pratica

\footnotetext{
${ }^{8}$ Nesse caso, à parte o heroico, o sáfico, o alexandrino e suas variantes, há sonetos em nove, treze e até quinze sílabas. Note-se que a arte maior varia de língua, pois em italiano e em espanhol um verso de nove sílabas corresponde ao ponto de partida da arte menor e, conforme destacado, o hendecassílabo é, nessas línguas, o ritmo de verso mais praticado na criação de sonetos.

${ }^{9} \mathrm{Na}$ poesia brasileira do Modernismo, um caso variante é o poema "Gazal em louvor de Hafiz" (publicado em Lira dos Cinquent'anos, em 1940), de Manuel Bandeira, que apresenta sete dísticos no seguinte esquema de rimas: AA// $\mathrm{BA} / / \mathrm{CA} / / \mathrm{DA} / / \mathrm{EA} / / \mathrm{FA} / / \mathrm{GA}$. Neste esquema de Bandeira observa-se que há consonância apenas entre os versos pares do segundo ao sétimo dístico, a partir da rima emparelhada do primeiro.
} 
o soneto sem deixar de fazê-lo conforme a estrofação italiana, em dois quartetos e dois tercetos, sempre empregando o verso decassilábico conforme o padrão da língua portuguesa, e se além disso jamais emprega rimas consoantes nem assonantes, à maneira de Spencer, um soneto desse suposto poeta seria uma espécie de italiano branco. Se somente italiano, mantendo deste tipo o esquema de rima de sua tradição petrarquiana (ABBA/ABBA/CDC/DCD) de modo assonante, o resultado seria uma deriva ou variante.

No século XX, o Nobel chileno Pablo Neruda foi assíduo praticante do soneto, e dentre a variedade de sua produção dessa forma fixa, Neruda recorreu bastante ao soneto livre (ou anisossilábico), i. e., aquele que não apresenta métrica regular (nem heterometria). $\mathrm{O}$ soneto livre pode apresentar rimas (a esmo ou segundo um esquema, logo, em duas variantes - que se tornam quatro, considerando-se que a rima pode ser consoante ou assonante), assim como pode ser branco (outra variante). Em tempo, embora por outro exemplo, os poemas "Remissão", "Tarde de maio", "Amar" e "A máquina do mundo", do livro Claro enigma (de 1951), de Carlos Drummond de Andrade, são, respectivamente, evidentes casos de: soneto, livres (o segundo e terceiro) e variante de terça rima. Não há como encontrar um padrão (senão próprio do poema apenas) em "Amar" e em "Tarde de maio", e isso obriga qualquer analista a considerá-los livres. No entanto, embora não dado em uma amostragem com nenhum caso equivalente, qualquer analista identificará que "Remissão" é um soneto com variante do esquema de rima italiano (ABAB/ABAB/CDE/CDE) com predominância de versos heroicos. Isso significa dizer que a forma fixa é assinalável pela variedade mesmo que um dado poema esteja em uma amostragem sem equivalentes, ou seja, a recorrente produção de uma forma fixa desde sua origem funda, in abstracto, um modelo que serve tanto à criação quanto à análise. Esse princípio autoriza qualquer 
analista a descrever "A máquina do mundo" como um poema em tercetos variantes de terça rima.

O princípio da variedade da fixidez notificado decorre do princípio da "igualdade na quantidade" (aequalitas numerosa), advindo do livro VI da obra De musica, de Santo Agostinho. A fórmula disso não é de difícil compreensão: algo pode ser categorizado como de determinada forma porque partilha em base de característica fundamental (recorrente) comum em relação a outros objetos, ainda que no conjunto todos os objetos possam ser variáveis entre si - veja-se a dentição dos seres humanos: os dentes de uma pessoa não são iguais, mesmo os sisos, mas são todos identificados como dentes, assim como a dentição de uma pessoa não é igual à de outra. Logo, quando um objeto do mundo não partilha em base de característica fundamental em relação a outro, estes jamais pertencem a uma forma fixa. Por experiência de leitura, qualquer analista pode dizer que a maioria dos poemas escritos dos fins do século XIX até hoje em dia no Ocidente não é de forma fixa, pois aquilo que partilham entre si é próprio da arte, não da forma. No campo formal, o que chama a atenção da crítica quando Claro enigma vem a público é o dado de que neste livro Drummond recorre a formas e padrões fixos como jamais havia feito. A formalidade fixa recorrente em Claro enigma pode ser identificada entre poemas da obra, no entanto, isso é dispensável para a discussão deste artigo, pois sobretudo a formalidade daquele livro de Drummond é identificável pela quantidade de poemas que são de forma fixa segundo esta categoria da arte poética in abstracto. Esse princípio alicerça toda a discussão a ser desenvolvida doravante. A discussão será ilustrada por um corpus próprio da poesia brasileira, que inclui o soneto "A um poeta", de Olavo Bilac (1996, p. 297); o sonetilho "Epitáfio", de Vinícius de Moraes (1946, s/p); o soneto "Oficina irritada" de Carlos Drummond de Andrade (1967, p. 245); e o poema "O martelo", de Manuel Bandeira 
(2013, p. 25). A análise estará calcada no soneto como forma fixa a partir daquela síntese descrita anteriormente (no início do primeiro parágrafo) em observação de sua variedade formal interna e externa, ou seja, do molde, da versificação, da estrofação, do esquema de rimas, do ritmo e de sua tonalidade. A abordagem crítica considera o movimento cada vez mais dinâmico do soneto como forma fixa na Modernidade, incluindo sua origem no Duecento italiano.

O soneto surge em uma época de trânsito, dos fins da Idade Média ao início da Idade Moderna, historicamente marcada no intervalo do Humanismo ao Renascimento, este período que embora tenha sido propriamente um domínio italiano expandiu seus valores para a Europa e, por extensão em coincidência com a máquina ultramarina da empresa de colonização, chega aos "novos continentes". Um fundamento de valor vindo da antiguidade grecorromana - alicerce canônico da formação civilizacional do Ocidente, sobretudo poética - opera discursivamente o soneto quando surge: trata-se da tríade clássica VERDADE-BELO-BOM, que atende ao princípio de UNIDADE conforme o valor de BEM (de âmbito moral e espiritual). Ainda que à época de surgimento do soneto, bem como no curso de sua formação variável até, pelo menos, à altura do nascimento do Romantismo nos fins do século XVIII, a categoria BELO da tríade clássica não correspondia à aesthesis no sentido do sistema das artes, tanto esta quanto as duas demais categorias incidiam nas produções artísticas e intelectuais. A aesthesis, lato sensu, como percepção do mundo conforme a inteireza entre Humanidade e Natureza, em acordo com o fundamento da tríade clássica, somente correspondia à beleza se correspondesse à VERDADE e ao BOM (ao justo, correto, devido). $\mathrm{O}$ soneto, desde sua forma pré-italiana, aquela praticada por seu inventor, Giacomo da Lentini, até o início da segunda metade do século XIX 
principalmente tinha o amor como tema. Como o período (primeiro terço do século XIII) de surgimento do soneto, bem como o território (a península itálica) correspondia a um domínio moral e espiritual fundamentalmente cristão católico, o amor somente seria tal - não se admitia relativismo - se de uma pessoa a outra se realizasse em conformidade a Deus, logo, em nome Deste. A percepção (própria do sentir) do amor somente seria devida a este sentimento se o espírito (o ânimo) humano correspondesse ao amor que Deus tem pela e doa à Humanidade, logo, o amor somente existia em um domínio de pureza, à parte dos corpos, embora coincidente com as pessoas. Perceber o amor de tal modo e dizê-lo faria o dizer equivaler ao verdadeiro e, portanto, faria com que fosse justo (BOM). Para responder devidamente àquela tríade, o soneto, devido a seu tema mais recorrente (ou principal), teve de surgir como forma fixa - há no conjunto de uma oitava e dois tercetos de Lentini o embrião da composição em dois quartetos e dois tercetos da apropriação feita do soneto por Guittone d'Arrezo, composição que toma corpo cerca de trinta anos depois. A oitava e o quarteto correspondiam a formas da poesia popular, enquanto o terceto correspondia à poesia erudita. A junção de um domínio e outro (popular e erudito) a respeito do amor tratava, pois, de dar azo ao amor propriamente dito, porque, do contrário, dizer do amor seria mera quimera. Aquilo que se disse sobre uma forma somente ser fixa porque variável está compreendido nisso, pois toda sorte de variedade do soneto (inglês, francês, estrambótico, acróstico, sintético etc.) jamais se afastou deste princípio mínimo de composição, a respeito de comungar algo pelo sentido que circulava no âmbito corriqueiro (do lugarcomum) com o mesmo algo pelo sentido que circulava no âmbito racional (da intelligentia, da erudição) em sua essência de ser, i. é., pelo que há de comum (diga-se, de próprio) naquele algo em relação aos dois âmbitos assinalados. Como se verá adiante, somente a partir da 
Modernidade recente - esta do surgimento do sujeito autocentrado, a partir de meados do século XVIII - isso será diferente, e embora isso o soneto ainda manterá um cerne mínimo de composição.

Esse modo de subjetividade que é motriz do soneto desde Lentini ao início do Romantismo é muito distinto de como a subjetividade passa a apresentar-se a partir deste período do pensamento e da estese. No soneto anterior à Modernidade recente o sujeito do enunciado é coincidente ao sujeito da enunciação de modo indelével, pois para dizer o sonetista precisava: dizer a respeito de ser em relação a Deus, uma vez que era de valor tácito entender que a essência humana é divina, dado que é advinda da criação do Pai segundo seu amor (princípio espiritual); e dizer-se a respeito de ser em relação a si, pessoalmente, consoante aos costumes autenticados (princípio moral) - muito embora entre os fins da Idade Média e o início da Idade Moderna a posição do sujeito em relação a Deus deixe, como é de conhecimento, de ser Téo para ser Antropocêntrica ${ }^{10}$. Somente de modo anacrônico ou estritamente teórico - e neste caso in vitro ou por obra de uma hermenêutica atual de crítica literária - pode-se tratar o sujeito do enunciado de um soneto ou da sonetologia de Dante como uma persona, uma deriva subjetiva ou forma de uma discursividade metonímica. Por mais que Beatrice Portinari não tenha sido efetivamente amada por

${ }^{10}$ Exemplar disso é o caso de Guido Cavalcanti, pois em seus sonetos o amor figura como uma perdição que derrui a razão. Embora isso, observe-se que em Cavalcanti e poetas posteriores que assumem essa ou outra posição sobre o amor - Louise Labé e Camões se dão ao amor mais corporalmente, embora tenham sido petrarquistas - é o pecado (queda do ou falta com o princípio espiritual) que está em cena. Logo, porque o pecado macula o amor, este se torna uma perdição, no entanto, uma vez que o pecado estava em debate, logo, a atenção ao Deus não havia se perdido, apenas se deslocado em relação à posição do sujeito, que se era meditativo em poesia (ou reflexivo ou filosófico), como Cavalcanti, deixava de ser teológico, como os poetas anteriores, mais adidos à ideia medieval europeia de mundo. 
Dante, e, logo, tenha sido estritamente uma alegoria para o amor, tudo que se refere a ela na poesia dantesca sobre o amor coincide com o próprio sentir e pensar do sujeito da enunciação, o Dante empírico, sujeito civil. À época, e durante muito tempo, poetas não tratavam de um tema conforme o sentir e o pensar alheios, como é frequente na poesia da Modernidade recente. O sujeito autocentrado dessa Modernidade é aquele que, voltado para si mesmo, torna o eu uma figura semântica, um valor de sentido, que varia de dizer-se a não se dizer, uma vez que, em tese, tem o controle sobre a voz do eu que diz eu sobre si mesmo. Já o sujeito anterior, diga-se centrado, diz-se (princípio moral). Isso jamais deu em mero confessionalismo, pois esse dizer-se sempre esteve coadunado ao ser humano porque é ser em Deus (princípio espiritual) - isso, conforme se enfatizou, ocorreu somente a respeito do soneto desde o surgimento até meados do século XVIII. Havia, portanto, uma forja de universalidade ideologicamente operatriz do que era autenticado como moral e espiritual ${ }^{11}$.

A respeito da composição formal do soneto é relevante considerar também que esse gênero poético já surge com fundamento de fixidez formal pela força histórica da ideologia formativa dos gêneros literários. Tanto a Poética medieval quanto a Poética renascentista, logo, também aquela de trânsito de quando o soneto se refina, a do Humanismo, emulavam fundamentos da antiga Poética grecorromana.

${ }^{11}$ No estado da pesquisa, até então não se encontrou nenhum soneto distinto dessa prédica. E, sim, trata-se de uma prédica porque embora o sujeito centrado jamais seja distinto em poesia do que sente e pensa empiricamente, ele estava socialmente formado (educado) a ser assim. Quando aprendia a Poética e por ela tornava-se poeta, e não somente leitor, o sujeito empírico praticava o soneto conforme essa prédica, que, além de autenticar um fundamento moral e espiritual, autorizava o soneto conforme certas regras, à guisa manualesca incluindo nisso a "igualdade na quantidade", i. é., o princípio de variedade da forma. 
Observe-se a respeito disso que em sua forma original (de Giacomo da Lentini) o soneto era composto de uma oitava e dois tercetos. Isso evidencia, no embrião do soneto, o aspecto ternário do surgimento da estrofe por obra de Í́bico - poeta grego arcaico que em meados do século VI a.C. divide, pela primeira vez na história da poesia ocidental, tantos seus poemas eróticos (amorosos dedicados a meninos) quanto seus poemas heroicos (dedicados a mitos menores ou menos frequentados) em três partes. Sabe-se que a antiga poesia grega era para, sobretudo, ser transmitida oralmente (via canto ou récita), com isso a divisão de Íbico consistia em: estrofe como o movimento que o coro fazia à direita, dirigindo-se ao público; antiestrofe como o movimento contrário do coro, quer dizer, dirigido à esquerda do público; e epodo como o movimento de união de vozes que fazia o corifeu dirigir-se ao centro em relação ao público. Nisso, tal divisão ternária compunha uma apresentação (estrofe), um desenvolvimento (antiestrofe) e uma síntese como inferência ou desfecho (epodo). Esse princípio performático lógico-discursivo já existia na poesia anterior a Íbico, no entanto tornase ainda mais racionalizado por obra deste poeta, que substancia em unidades coesas e coerentes em si mesmas cada movimento de um poema. A disposição dos movimentos em partes destacadas que evidenciam uma diferença entre uma e as outras passa a formular, por exemplo, a ode, como se tornou específico da ode pindárica. Além disso, na medida em que a poesia coral se torna infrequente e que a escrita toma o lugar da oralidade em poesia, cada movimento assume restrição formal, pois sua dramaticidade de performance se perde. À parte a história da estrofe na poesia ocidental, que inclui como algumas estrofes se tornaram autônomas, quer dizer, constituíram poemas propriamente ditos, por analogia observa-se que o soneto lentiniano traz consigo ecos da origem da estrofe - que, via de regra, conforme o formalismo da escrita poética, assimilou a antiestrofe e o epodo e, 
inclusive, perdeu o princípio de movimento. Isso ocorreu - é uma conjectura, pois como tese exigiria uma pesquisa etimológica e filológica - porque em grego $\sigma \tau \rho o \varphi \eta ́$ foi transliterado em strophe pelo latim, termo que é correspondente a "estância" em português pelo termo stanza, do italiano. Em tempo, apresentação (virtude da estrofe), desenvolvimento (virtude da antiestrofe) e síntese como inferência ou desfecho (virtude do epodo) se observa nas estâncias do soneto lentiniano: a oitava é a apresentação, o primeiro terceto é o desenvolvimento e o segundo terceto é a síntese. De Lentini a d'Arezzo essa progressão lógico-discursiva do soneto não se perde, embora este poeta tenha reestrofado o soneto em dois quartetos e dois tercetos, conforme já foi observado. Não dá para saber exatamente qual foi o motivo disso, no entanto, pode-se conjecturar que decorreu de a apresentação parecer muito extensa, pois, a partir d'Arezzo - e principalmente a partir de Petrarca -, o primeiro quarteto corresponde à apresentação; o segundo quarteto e o primeiro terceto, ao desenvolvimento; e o segundo terceto, à síntese ${ }^{12}$. No caso do Parnasianismo - certamente devido às bases filosóficas deterministas do Naturalismo - os dois primeiros versos do segundo terceto correspondem a algo equivalente a um clímax, como na prosa de ficção, e o último verso à síntese originalmente correspondente a todo o segundo terceto. A este verso final do último soneto o Parnasianismo chamou de chave-de-ouro. Vale notificar que no soneto inglês (em três quartetos e um dístico, seja no modelo branco de Spencer ou no modelo distintamente rimado entre as estrofes de Shakespeare

${ }^{12}$ Empiricamente, esta conjectura se sustenta porque toda sorte de gênero textual de natureza argumentativa ou parcialmente argumentativa (caso dos sonetos e da poesia meditativa) sempre apresenta o desenvolvimento de modo mais extenso do que a apresentação, bem como apresenta esta de modo mais extenso do que o desfecho. 
$\mathrm{ABAB} / \mathrm{CDCD} / \mathrm{EFEF} / \mathrm{GG})$ a apresentação do soneto lentiniano coincidente na oitava retorna à forma de oito versos, pois equivale no caso inglês aos dois primeiros quartetos. Não foi o caso de nossa investigação, mas decerto vale a pena pesquisar se a chave-de-ouro parnasiana tem relação com o dístico final do soneto inglês, que é correspondente à síntese ${ }^{13}$.

Chega-se, com a discussão do parágrafo anterior, ao ponto em que se identifica a base do soneto, mantida desde seu surgimento até a atualidade: poema de ritmo e harmonia equilibrados quase restritamente a catorze versos cujo tema responde a uma progressão equivalente a: apresentação, desenvolvimento e síntese, de sorte que o sentir se expressa de modo jamais separável do pensar. Embora essa unidade tão coesa e coerente da textualidade estética do soneto tenha sido formada pela força ideológica da deferência de um cânone - o qual propagou principalmente Petrarca e Shakespeare, e, ressalte-se, Camões, no caso da língua portuguesa -, a recepção geral assimila a forma do soneto como algo preciso e exato, ainda que se reconheça, no mínimo, o molde italiano e o molde inglês - até porque o terceiro molde mais canônico varia em relação ao italiano apenas pela métrica e pelo esquema de rimas dos tercetos, é o caso do molde francês. A discussão desenvolvida até então reforça que não há precisão nem exatidão no soneto senão in abstracto. Em depoimento pessoalmente dirigido a mim durante uma entrevista em 2008 em seu apartamento na Rua Tonelero em Copacabana, Rio de Janeiro, o poeta Gerardo Mello Mourão comparou o soneto a um violão, asseverando que este instrumento é análogo a sua

${ }^{13}$ A chave-de-ouro pode ser entendida como advinda do Classicismo, considerando este termo como uma espécie de redução de toda a Idade Clássica, ou seja, do Renascimento ao início do Iluminismo. No entanto, não é observável que dos renascentistas - e até mesmo de seus predecessores no soneto, Dante e Petrarca - adiante o último verso do segundo terceto seja uma síntese do soneto, diferentemente do que ocorre nos sonetos parnasianos. 
formalidade fixa, para finalmente dizer que se alguém não souber "tocar" um soneto que não o "toque". Isso faz bastante sentido, pois, além de diversas peças musicais as mais distintas (isso é análogo à variação temática e estilística do soneto), há tipos diferentes de violão: o clássico, o TH5, o Folk, o ETN 10, o Jumbo etc. (isso serve de modo análogo à variedade métrica e de rima do soneto). Em suma, independentemente do tipo e das composições musicais, se o instrumento é um violão há nisso a pertinência do princípio de "igualdade na quantidade". O mesmo vale para o soneto, salvo a restrição a respeito de a matéria do soneto (como de toda a poesia) ser um idioma, ou lato sensu, a linguagem verbal, e isso torna o debate sobre o soneto mais complexo, pois a materialidade própria da engenharia musical é muito mais concreta e, logo, não torna possível tantas variedades desse instrumento em relação à linguagem verbal, dado que todo idioma é muitíssimo mais variável, a ponto de sê-lo não somente de nação a nação, de região a região e de comunidade a comunidade, mas também de pessoa a pessoa.

$\mathrm{Na}$ Modernidade recente, por força do Iluminismo com sua filosofia pragmática de política liberal e economia pré-capitalista, a tríade clássica VERDADE-BELO-BOM como UNIDADE do valor de Bem é cambiada por LIBERDADE-FELICIDADE-PAZ, cuja base teórica pode responder a esta fórmula pronominal: OUTRO-EU-NÓS. O OUTRO deve ser livre; EU em relação ao OUTRO, por não deixar de ser um "eu mesmo", é igualmente OUTRO, e ambos, EU e OUTRO, constituem NÓS. Assim, a LIBERDADE é de cada um; a FELICIDADE equivale a EU, se este é livre; e a PAZ, no conjunto, somente é possível se OUTRO é livre e se EU é feliz, o que resulta em OUTRO e EU serem NÓS. O modo de subjetividade decorrente dessa tríade iluminista é bem distinto daquele decorrente da tríade clássica, 
sobretudo porque jamais será singular. Quer dizer, se alguém apenas pode ser feliz sendo livre, e alguém é sempre EU e OUTRO, logo, na expressão poética o sujeito do enunciado necessariamente não coincidirá com o sujeito da enunciação, uma vez que ambos serão independentes, ainda que jamais indiferentes - daquele a este e viceversa. Isso significa que o ser no eu inculcado por força de um controle conjunto em forjada unidade entre moralidade e espiritualidade deixa de ser mutuamente integrante para ser paralelamente diametral. Por isso o sujeito autocentrado da Modernidade recente tanto se diz dizendo-se quanto diz sem dizer-se. Isso assume uma propagação de tal modo exponencial que, por exemplo, atualmente é possível flagrar-se modos distintos de subjetividade em um único livro de poesia de um mesmo poeta. Tudo que do Romantismo ao Modernismo correspondia a uma distinção de modos de subjetividade de um mesmo poeta de uma época a outra (no Romantismo) a uma distinção não somente de época a época, mas também de livro a livro (no Modernismo), atualmente se torna uma distinção de poema a poema, quando anteriormente - no caso do soneto, de Lentini a meados do século XVIII - limitava-se no máximo à maturidade do poeta, dado que na obra deste o sujeito do enunciado e o da enunciação eram coincidentes. De Petrarca mais jovem a mais velho, a concepção platônica de amor que assume em seus sonetos se torna tanto mais bem resolvida porque mais bem expressada esteticamente, logo, jamais distinta. Sonetos à parte, para que fique mais evidente essa observação, entre os poemas "Marabá" e "Se se morre de amor", de Gonçalves Dias, a concepção de amor do sujeito do enunciado varia, pois enquanto naquele poema homônimo ao nome da personagem que monologa no texto o amor jamais será possível, porque Marabá tem forma materialmente exógena dos demais membros de sua tribo; já em "Se se morre de amor" toda a exposição sobre quando se morre de amor e quando não se morre leva a entender que o amor 
propriamente dito é indistinto à diferença material entre os corpos, digase à etnia. Além do que, em "Se se morre de amor" há duas concepções de amor: a deste sentimento de fato, que se é presente poderá, sim, levar à morte; e a deste sentimento em uma espécie de pseudo-forma - dirse-ia, mais contemporaneamente, se confundido com paixão ou com tesão - que, como tal, jamais levará à morte. No segundo poema referido de Gonçalves Dias a dicotomia “amor e amor" não existe por obra do poeta, mas porque este capta essa discussão do mundo. Uma vez que tal discussão estava no mundo, diga-se entre o lato e o stricto sensu, logo, já era próprio da época a autocentração do sujeito inclusive no âmbito corriqueiro, do lugar-comum.

A categoria LIBERDADE da tríade iluminista no lugar de VERDADE da tríade clássica é uma espécie de escorpião encalacrado, um palito de fósforo aceso dentro da caixa dentre os demais palitos. $\mathrm{O}$ princípio de UNIDADE da tríade clássica, embora isto seja obra de um controle ideológico, é equivalente à categoria de VERDADE, assim como às demais, pois o uno é aquilo que por inculcamento de valores que se tornam tácitos coaduna todos em um todo. Já a LIBERDADE é variada por princípio: começa em um indivíduo e neste termina porque também começa em outro, tornando-se algo que ilusória, porque jamais universal, uma vez que sempre restrita, pois isso não permite que alguém vá até outrem efetivamente, quer dizer: alguém é livre em si, mas, se intervir no outro, tira deste a condição de ser livre e dá ao mesmo a possibilidade de igualmente ser intervindo, tirando de si sua condição de ser livre. A VERDADE da tríade clássica vai a todos, mas há força de poder nisso; a LIBERDADE não deixa de responder a uma força de poder, no entanto, pressupõe que o poder é cambiável, e, de câmbio em câmbio, ela cada vez mais é algo somente no horizonte, e o horizonte, se alcançado, sempre aponta a outro horizonte. Nisso, o soneto a partir do Romantismo varia em sua já variante forma 
originária, varia em tema - inclusive em um mesmo tema -, bem como, conforme aconteceu à poesia em geral, varia em distinguir sujeito do enunciado de sujeito da enunciação. Tal fator leva a ter tornado possível aplicarem-se os fundamentos da poesia verbi-voco-visual sobre o soneto e também a encontrarem-se poemas que mantêm certa relação com o soneto, que parecem dele advir, porém, expressivamente por força de desrealização do gênero, apresenta-se de modo bem diferente, como é o caso do poema "O martelo", de Manuel Bandeira, conforme será abordado. Segundo já se insinuou, a FELICIDADE e a PAZ são igualmente individuais, até porque, se não fossem, não formariam uma tríade. Se alguém é livre em si, somente consigo poderá ser feliz e, por sua vez, somente entre os demais de acordo consigo estará em paz. Os regimes autoritários e os regimes democráticos formados a partir dos fins da segunda metade do século XIX são prova disso. Para os regimes nacionalistas totalitários (franquismo, fascismo e nazismo, por exemplo), a felicidade do povo levaria à paz somente se os outros povos se rendessem à identidade da nação sob ordem despótica, e, internamente, se algum indivíduo discordasse dessa política, deveria ser reprimido, pois a tríade iluminista foi lida em tais regimes com base na unidade da nação e não na unidade do indivíduo, segundo a concepção política de mundo do déspota e de seus seguidores - nisso, é patente um controle político público a partir de uma concepção individual de mundo, fazendo com que a tríade iluminista, embora muito mais para mal do que o previsto, esteja autenticada. No excedente, o anarquismo é diametral a isso, e como uma abóbada fragmentada - quer dizer, apenas com vestígio do que fora abóbada -, na vida comum hodierna cada indivíduo exige para si autonomia na mesma medida em que exige dos demais a aceitação dessa autonomia, como se ignorasse que os demais são igualmente indivíduos que, por sua vez, um a um também exigem para si autonomia e aceitação dessa autonomia. 
Embora seja possível desdizer-se que o poema "Áporo", do livro $A$ rosa do povo (de 1945), de Drummond, não é um soneto, é bastante flagrante que o é, pois a composição estrófica é do soneto, bem como o ritmo em tetrassílabos (terço prosódico do decassílabo) é do sonetilho (soneto em arte menor, i. é., de métrica igual ou inferior a oito sílabas poéticas, no caso da língua portuguesa). A rima assonante de disposição irregular diz respeito àquilo que foi dissertado a respeito dos efeitos da tríade iluminista sobre a Modernidade recente. Por sua vez, o tema alegoriza na polissêmica figura do áporo o indivíduo reprimido por força da política de um regime de exceção, mas que, mantendo-se militante na marcha subversiva contra o regime despótico, consegue brotar sua liberdade, tornando-se feliz, o que o faz encontrar a paz. A escolha da figura alegorizada é bem inteligente, pois áporo é tanto um problema difícil de se resolver, conforme está dado no primeiro quarteto; quanto um inseto himenóptero (a exemplo das vespas), que escava um espaço em busca de um lugar próprio, segundo está dado no segundo quarteto e no primeiro terceto; como também um gênero da família orquidácea, imagem que toma forma no último terceto. Embora temas políticos não sejam estranhos ao soneto - a exemplo do tema do “desconcerto do mundo', da poesia de Camões -, o sujeito do enunciado em “Áporo" é facetado em terceira pessoa singular, uma forma de não se dizer dizendo-se, e se faz expressivamente sensível na figura alegorizada, chamando a atenção não para o eu que diz eu sobre si mesmo, mas para o eu que se alheia, que se desinteressa de si para se interessar pelo outro, uma vez que na base teórica da tríade iluminista que ilustra o surgimento dos modos de subjetivação da Modernidade recente há a fórmula pronominal anteriormente comentada OUTROEU-NÓS, na qual OUTRO e EU são ambos, entre si, recíprocos e reversíveis. Isso jamais é observável seja em Camões ou outro sonetista do período quando o sujeito era centrado, porque a tríade clássica foi 
forjada idealmente a partir de fora dos indivíduos, diz respeito ao ser e ao dever ser na existência, e não ao estar como dever estar. A fórmula iluminista, ainda que também seja obra de uma forja idealizada, tem o indivíduo como ponto de partida. Ela é falha nessa base, pois é (como foi) passível de interpretação variada (como no caso dos regimes autoritários) como uma potência explosiva, que dilacera a subjetividade una em diversos modos subjetivos.

Considerem-se os sonetos "A um poeta" e "Oficina irritada", respectivamente de Olavo Bilac e Carlos Drummond de Andrade:

Longe do estéril turbilhão da rua,

Beneditino escreve! No aconchego

Do claustro, na paciência e no sossego,

Trabalha e teima, e lima, e sofre, e sua!

Mas que na forma se disfarce o emprego

Do esforço: e trama viva se construa

De tal modo, que a imagem fique nua

Rica mas sóbria, como um templo grego

Não se mostre na fábrica o suplício

Do mestre. E natural, o efeito agrade

Sem lembrar os andaimes do edificio:

Porque a Beleza, gêmea da Verdade

Arte pura, inimiga do artificio,

É a força e a graça na simplicidade.
[느요 $\underline{-}-\underline{10]}$

[4- $-\underline{6}-\underline{10]}$

[2- $-\underline{6}-10]$

[ㅁ-ㅁ- $\underline{6}-8-10]$

[느요 $\underline{-}-10]$

[2-4- $\underline{6}-\underline{10]}$

[2- $-\underline{6}-8-\underline{10]}$

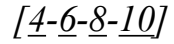

[믄 $\underline{6}-\underline{10}]$

[2- $-\underline{6}-\underline{10]}$

[므- $\underline{6}-\underline{10}]$

[2- $-\underline{4}-\underline{6}-10]$

[믄 $-\underline{-10]}$

[므는 $-\underline{6}-\underline{8}-\underline{10]}$

(BILAC, 1996, p. 267)

Eu quero compor um soneto duro como poeta algum ousara escrever. Eu quero pintar um soneto escuro,

[2-5-8-10]

[4-7-10]

[2- $-5-8-10]$ 
seco, abafado, dificil de ler.

Quero que meu soneto, no futuro, não desperte em ninguém nenhum prazer. [ㅁ-ㅁ-8-10]

E que, no seu maligno ar imaturo, ao mesmo tempo saiba ser, não ser.

Esse meu verbo antipático e impuro há de pungir, há de fazer sofrer, tendão de Vênus sob o pedicuro.

Ninguém o lembrará: tiro no muro, cão mijando no caos, enquanto Arcturo, claro enigma, se deixa surpreender.

Observe-se que em ambos os sonetos o molde é italiano. Contudo, em formato, apenas "A um poeta", de Bilac, é propriamente italiano propriamente, pois além de conservar o molde em catorze versos divididos em dois quartetos e dois tercetos, e além de o ritmo ser decassilábico (como é de tradição em português), o esquema de rimas é petrarquiano: $\mathrm{ABBA} / \mathrm{ABBA} / \mathrm{CDC} / \mathrm{DCD}$, ou seja, os quartetos rimam de modo interpolado sempre nas duas mesmas rimas, os tercetos estão compostos conforme o modo alternado da terça rima. Além do molde da divisão estrófica italiana, o soneto de Drummond também conserva o ritmo decassilábico, no entanto, seu sistema de rimas é composto do primeiro quarteto ao segundo terceto conforme a terça rima, contudo, mantém apenas duas rimas: $\mathrm{ABAB} / \mathrm{ABAB} / \mathrm{ABA} / \mathrm{AAB}$, em vez de fazer, como seria esperado de um soneto em terça rimas: $\mathrm{ABAB} / \mathrm{CBCD} / \mathrm{CDC} / \mathrm{DEE}$ - tendo-se em atenção que os dois versos finais desse tipo de soneto são emparelhados porque a terça rima é um modelo estrófico ternário enquanto o soneto é um gênero poético 
binário no que diz respeito à quantidade dos versos e à maneira de harmonizá-los.

Em "Oficina irritada", conforme destacado ao lado dos versos, a tonalidade não é sempre equivalente ao decassílabo mais recorrente em português, o heroico. O primeiro quarteto do soneto de Drummond apresenta cesura média em sílabas ímpares de modo alternado (5-7-5-7) em consonância ao esquema de rimas. Os versos pares daquele quarteto são decassílabos em gaita galega (ou moinheira), que é uma variante do decassílabo sáfico, deste se distinguindo pelo deslocamento da cesura da oitava para a sétima sílaba. $\mathrm{O}$ ritmo sáfico de certo modo se mantém no quarteto porque os versos ímpares apresentam pós-tônica na oitava sílaba. Já o segundo quarteto tem a tonalidade do heroico, e, embora isso, ainda de modo alternado, os versos pares apresentam pós-tônica na oitava sílaba. Há um refinamento nisso, pois o segundo verso é um martelo com pós-tônica e o quarto verso é um decassílabo pentâmetro iâmbico. Também alternadamente os versos ímpares são heroicos, sendo o primeiro uma variante com pré-tônica na quarta sílaba. No primeiro terceto, sequencialmente, o soneto apresenta: um decassílabo em gaita galega, um sáfico e um pentâmetro iâmbico, mantendo, na média, a tonalidade do sáfico. No segundo terceto, todos os versos são heroicos, mas observa-se que o primeiro verso tem pós-tônica na sétima e o segundo na oitava sílaba, fazendo ecoar novamente o verso sáfico, enquanto que o terceiro verso é um martelo. Equilibradamente no conjunto, as estrofes ímpares têm predominância sáfica, e as estrofes pares, heroica. De maneira bastante complexa, "Oficina irritada" é produto de uma engenharia poética binária duplamente duplicada da estrofação ao esquema de rimas, destes ao ritmo e à tonalidade. $\mathrm{O}$ poema de Drummond apresenta um eu lírico que declara com severidade o desejo de escrever um soneto difícil de ser lido enquanto o próprio soneto progride, ou seja, o eu lírico diz o que deseja fazer enquanto faz, pois o sistema métrico e prosódico do soneto é de difícil leitura e, mais 
ainda, de difícil vocalização, devido a, conforme foi analisado, a variação cambiada entre versos de tonalidade sáfica e heroica, isso leva em conta, a mais, que o sistema de pontuação gráfica empregado por Drummond é formal, respeita a norma gramatical, o que torna tanto a leitura quanto a vocalização ainda mais difícil, uma vez que a pontuação gráfica marca pausas lógicas distintas das pausas de cesura, pois engendra a coesão e a coerência do texto. Dizer que deseja fazer um soneto difícil de ler enquanto o faz assinala um modo de subjetividade próprio da Modernidade recente, pois isso identifica um sujeito que recorre a um gênero da tradição poética à altura de Claro enigma, livro onde "Oficina irritada" foi publicado, o soneto tinha um pouco mais de setecentos e vinte anos que fora inventado contra o qual esse sujeito fala enquanto o produz. Além disso, somente a partir do século XX, tendo como marco o Modernismo, identificam-se peças poéticas advindas da tradição submetidas a variantes tão peculiares - uma pesquisa que buscasse de meados do século XVIII somente em português qualquer soneto com engenharia similar ao de Drummond seria exaustiva e, quiçá, improdutiva, e uma pesquisa que fizesse o mesmo da primeira metade do século XVIII até 1526, quando Sá de Miranda introduziu o soneto na língua portuguesa, seria indubitavelmente improdutiva. Logo, dentro da Modernidade recente, apenas a partir da mais próxima, aquela que se inicia com o Modernismo, ampliou os modos de subjetividade a ponto de a variação do soneto deixar de ser somente sublinhada entre moldes (italiano, inglês e francês), estilos (lentiniano, petrarquiano, spenceriano, shakespeariano, cervantino etc.) e estruturação (soneto estrambótico, acróstico, glosado, sintético, alternado, interpolado etc.) para receber um tratamento particular - e nisso, único, pois o modo de composição de "Oficina irritada" não é retomado por Drummond em sua obra.

De volta ao soneto de Bilac, é visível que, diferentemente de Drummond, o poeta parnasiano defende uma ideia de prática poética que responde aos princípios clássicos da clareza e da concisão, chegando a 
evocar as categorias VERDADE e BELO (por "Beleza") e a deixar implícita a categoria BOM da tríade clássica - neste caso, os dois versos finais do soneto implica naquilo que é justo porque verdadeiro e belo. Como essa concepção poética advém do Classicismo, a composição de "A um poeta" responde mais diretamente à tradição italiana de estilo petrarquista do soneto em língua portuguesa. Além do que já foi assinalado sobre o esquema de rima, o ritmo decassilábico do soneto de Bilac é predominantemente heroico. Destacam-se em diferença o primeiro verso de cada quarteto, pois são sáficos. No primeiro quarteto há duas variantes de heroico, uma com prétônica na quarta e outra na segunda sílaba, e, no mais, o quarto verso é um pentâmetro iâmbico. $\mathrm{O}$ segundo e o terceiro verso do segundo quarteto também são variantes heroicas, apresentando-se o segundo com duas prétônicas (na segunda e na quarta sílaba) e o terceiro com pré-tônica na segunda e pós-tônica na oitava sílaba. A ocorrência de vestígio rítmico sáfico está distribuída irregularmente nos dois quartetos, considerando-se o primeiro e quarto verso do primeiro, e o primeiro, o terceiro e o quarto verso do segundo, e no último do soneto, que é um pentâmetro iâmbico. Vale acrescentar que no primeiro terceto os versos ímpares são martelos, bem como no verso par do segundo terceto. Embora sem apresentar a mesma engenharia de Drummond, Bilac também operou seu soneto de modo binário entre a tonalidade heroica e sáfica do ritmo decassílabo. A ausência de um engenharia tão delicada como a de Drummond no soneto de Bilac se entende pelo estado de mundo da Modernidade recente, uma vez que, embora moderno, o Parnasianismo elege o soneto como gênero poético por excelência a serviço da expressão lírica, i. é., a própria escola parnasiana que faz a eleição, e não um poeta em específico. Drummond vive uma época em que não há gênero em específico eleito para a expressão lírica, logo, quando este poeta decide escrever um soneto, pode modalizar-se subjetivamente de maneira muito mais livre do que um poeta como Bilac, que responde a um estatuto estético de escola fundamentada em pressupostos bastante rígidos, 
fechados, restritos. Um consideração importante é que a expressividade metapoética de "Oficina irritada" é bastante própria do século XX, quando mais frequentemente se fez poesia sobre poesia tratando-se do poetar pelo gênero, pela textualidade, pelo estilo ou por uma concepção poética ${ }^{14}$. Já em Bilac a metapoesia é dada a partir do poeta mesmo, como classe artística da arte verbal, alegorizado na figura do monge (Beneditino) que implica metaforicamente em isolamento, claustro. $\mathrm{O}$ poeta da metapoesia de Drummond, por sua vez, é aquele que diz eu sobre si mesmo, como se o próprio sujeito empírico dissesse: eu quero fazer, eu estou fazendo e eu fiz um soneto de tal maneira. Embora as considerações sobre "A um poeta", na sonetologia anterior à segunda metade do século XVIII será pouquíssimo frequente o emprego de uma tonalidade diferente, como Bilac faz ao cambiar heroicos com sáficos. Logo, Bilac já é de um período em que uma variação mais intensa do soneto é possível, desde que não haja comprometimento do ritmo. Nisso, observe-se que vocalizar um soneto que em uma mesma estrofe (caso do primeiro quarteto) lê-se um sáfico e depois um heroico com pré-tônica na quarta sílaba, para em seguida ler-se um heroico com prétônica na segunda sílaba e logo após um pentâmetro iâmbico, não é nada elementar, ainda que o ritmo do primeiro verso ecoe no segundo e no quarto, e o do terceiro ecoe no quarto, o qual, de resto, inclui todos os ritmos anteriores, pois um decassílabo em pentâmetro iâmbico em português acentua todas as sílabas pares - e são pares todas as sílabas acentuadas na

${ }^{14}$ Sabe-se que a metapoesia é bem antiga, embora no século XX tenha quase que se tornado a protagonista da poesia ocidental. No sentido de elogio às palavras, ou expressão do sujeito centrado enquanto canta, ou da desconfiança ou crítica sobre a poesia ou sobre o poeta, pode-se, a título de exemplo, em um recorte do século I a.C. ao século XVI, considerar: Horácio (65-8 a.C., "Exegi monumentum aere perennius", Odes, III, 30); Arnaut Daniel (1180-1210?, "Noigandres"); Dante Alighieri (1265-1321, Vida nova); Guillaume de Machaut (1300-1370, De toutes flours); e Luís Vaz de Camões (1524-1579 ou 80, "Cesse tudo que a musa antiga canta / que outro valor mais alto se alevanta", vv. 23-24, Os lusiadas). 
estrofe em análise -, ou seja, o pentâmetro iâmbico em português inclui o heroico e o sáfico, além disso, pode-se acrescentar, inclui dois terços do movimento rítmico do martelo e da gaita galega, bem como todos os casos pares de arte menor que produzem: sonetilhos octossilábicos, em heroico quebrado e tetrassilábicos.

Mesmo tendo sido não somente sonetista frequente, mas também praticado o soneto segundo os rigores italianos desta tradição em língua portuguesa, Vinícius de Moraes arroja ainda mais a variação desse gênero poético, como é o caso de "Epitáfio":

\author{
Aqui jaz o Sol \\ Que criou a aurora \\ E deu a luz ao dia \\ E apascentou a tarde \\ O mágico pastor \\ De mãos luminosas \\ Que fecundou as rosas \\ $E$ as despetalou. \\ Aqui jaz o Sol \\ $O$ andrógino meigo \\ E violento, que \\ Possuiu a forma \\ De todas as mulheres \\ E morreu no mar. \\ (MORAES, 1946, $s / p$ )
}

Esse poema é um sonetilho - um soneto em arte menor, quer dizer, em versos iguais ou inferiores a oito sílabas poéticas, conforme já foi observado. No passado, quando praticado, o sonetilho apresentava métrica regular, e esse não é o caso de "Epitáfio", que varia de modo heterométrico irregular entre cinco e seis sílabas. Irregular, sobretudo, 
porque são pentassilábicos (ou rendodilhos menores) os versos 1, 2, 6, $8,9,10,12$ e 14, enquanto são hexassilábicos (ou heroicos quebrados) os versos 5 e 13, e os demais $(3,4,7$ e 11) se lidos com sinalefa forçada são rendodilhos menores, mas se lidos com a devida dialefa, são heroicos quebrados. Evidentemente, por haver maior recorrência de redondilhos menores, o ritmo do sonetilho de Vinícius de Moraes é pentassilábico. Outra observação importante é que, embora em molde italiano, "Epitáfio" não apresenta um sistema de rimas regular: o segundo e o terceiro verso de ambos os quartetos rimam de maneira assonante. Pela distância, não se pode propriamente dizer que o primeiro verso do segundo terceto é assonante em relação a esses de ambos os quartetos, no entanto, o quarto verso do segundo quarteto e o segundo verso do primeiro terceto são assonantes entre si. De maneira consoante rimam entre si o primeiro verso do primeiro quarteto e o primeiro verso do primeiro terceto. Apesar da distância, como o verso é o mesmo, a sonoridade da coda do verso ecoa, à guisa de estribilho. Os demais versos não rimam. Logo, assim como a heterometria rítmica é irregular no sonetilho, também é irregular o sistema de rima, de modo a haver uma espécie de câmbio entre versos assonantes e brancos. Uma nota importante é que, embora Vinícius seja um poeta de geração modernista posterior a Drummond, "Epitáfio" é de 1939, logo, é anterior a "Oficina irritada", de $1951^{15}$. Essa observação sobre a época de criação de "Epitáfio" e de "Oficina irritada" é importante para

${ }^{15}$ Isso quanto ao ano de publicação de Claro enigma, pois não foi realizada a pesquisa genética do soneto. De todo modo, como os quatro livros imediatamente anteriores a Claro enigma são Novos poemas (de 1948), A rosa do povo (de 1945), José (de 1942) e Sentimento do mundo (de 1940), fica evidente que "Oficina irritada" é posterior a "Epitáfio" em pelo menos aproximadamente uma década. Embora isso, o sonetilho de Vinícius de Moraes foi publicado originalmente em Poemas, sonetos e baladas, em 1946, e depois em Livro de sonetos, de 1957, que teve sua republicação ampliada em 1967. 
assinalar que, lato sensu, o modo de subjetividade de Drummond e de Vinícius de Moraes são cambiáveis no domínio da Modernidade recente em trânsito da primeira para a segunda metade do século XX na poesia brasileira. Ainda a respeito dos modos de subjetividade, embora Bilac reclame a tríade clássica, a prática do soneto por parte dos poetas parnasianos é resultado de um sufrágio política e esteticamente pensado, com base no Naturalismo, em adversação ao Romantismo sobretudo tendo-se o conhecimento que o soneto quase não foi praticado pelos poetas românticos, os quais, também com base em um sistema de pensamento político e estético reagiram ao sistema predicativo de criação poética do Classicismo. Neste período que, por redução ou lato sensu pode ser assinalado do Humanismo ao Iluminismo, a prática frequente do soneto como gênero poético de excelência resulta de uma formação ideológica e estética que vai se constituindo progressivamente a partir da canonização efetiva de Dante e de Petrarca no século XVI. Antes disso, o soneto é quase que praticado na península itálica e apresenta algumas incursões na França. Logo, enquanto a prática do soneto anteriormente à segunda metade do século XVIII é obra de um construto civilizacional da cultura poética, no Parnasianismo sua prática é obra de um programa político e estético e, por isso, de um estado de ampliação da subjetividade.

Essa ampliação apresenta um extremo - que aqui não é defendido pela gênese do poema a destacar, mas por uma hermenêutica de análise - em ano aproximado à primeira publicação de "Epitáfio" (1939) e "Oficina irritada" (1951). Esse é o caso do poema "O martelo", de Manuel Bandeira, publicado em Lira dos cinquent'anos, em 1940. Não se trata de um soneto - não apresenta nenhum de seus moldes, ritmos e tonalidades, bem como nenhum de seus esquemas de rimas, à parte que esteja estruturado em versos brancos, assim como à parte seu tema, pois 
isto e aquilo estão incluídos nas variações do soneto em seus mais de setecentos e oitenta anos de existência na poesia ocidental. Eis o poema:

O Martelo

As rodas rangem na curva dos trilhos

Inexoravelmente.

Mas eu salvei do meu naufrágio

Os elementos mais cotidianos.

O meu quarto resume o passado em todas as casas que habitei.

Dentro da noite

No cerne duro da cidade

Me sinto protegido.

Do jardim do convento

Vem o pio da coruja.

Doce como arrulho de pomba.

Sei que amanhã quando acordar

Ouvirei o martelo do ferreiro

Bater corajoso o seu cântico de certezas.

(BANDEIRA, 2013, p. 25)

Não se pode dizer, diante de "O martelo" que, apenas por apresentar-se em catorze versos, lembra um soneto. Embora isso, dados os quase oitocentos anos desse gênero poético na cultura literária ocidental, é bastante convincente que, em geral, leitores e críticos se lembrem do soneto diante de poemas de catorze verso - e isso tem uma razão histórica provavelmente relativa à chegada do strambotto italiano a outras nações entre os séculos XIII e XVI. Contudo, em "O martelo", os cinco primeiros versos correspondem a uma apresentação (à guisa de proposição) do tema, os seis versos seguintes (já na segunda estrofe) correspondem a um desenvolvimento do tema, assim como os três versos finais correspondem a um desfecho - no caso, na forma de inferência. Ora, catorze versos organizados segundo o sistema de 
progressão textual lógico-discursivo do soneto implicam em motivo suficiente para provocar um analista a pensar no poema de Bandeira em relação ao soneto. Em sua formação poética, Manuel Bandeira tem de imediato o Simbolismo e o Parnasianismo, tanto francês quanto português e brasileiro, e, à distância, o Classicismo português. A esse respeito, é flagrante no conjunto da obra de Bandeira após sua adesão ao Modernismo o frequente emprego direto de formas da tradição - em conformidade a sua poesia anterior - e o frequente desfazer dessas formas para se coadunar aos modos de composição da poesia modernista. Nesse sentido, ainda que hermeneuticamente, pode-se dizer que "O martelo" corresponde a uma desrealização do soneto. Do que é um soneto, como se assinalou, há o embrião: os catorzes versos progressivamente em conformidade com uma apresentação, um desenvolvimento e um desfecho. Visto que há o embrião do soneto latente no poema de Bandeira, à parte hipótese e conjectura, é possível, sem equívoco, pensar "O martelo" como tal desrealização, quer dizer, com um desfazer de um gênero da tradição poética muito marcante na formação de Manuel Bandeira em relação a sua obra poética a respeito de sua adesão ao Modernismo na fase inicial desse período histórico da estética verbal no Brasil. Flagra-se nessa perspectiva que os modos de subjetividade da Modernidade recente levou os poetas do Alto Modernismo a esse tipo de prática porque eles foram educados, antes de desenvolverem sua obra, em uma época que, no caso de algumas nações do Ocidente - França e Brasil, por exemplo -, o antinômio Parnasianismo e Simbolismo correspondia ao que havia de moderno em poesia, poetas de tais escolas estéticas praticaram o soneto largamente, e no período pressupostos do Classicismo integravam a formação básica dos poetas. Isso não significa dizer que "O martelo" - conforme destacado anteriormente - seja um soneto, mas que os modos de subjetividade da Modernidade recente levaram os poetas até o ponto de 
desrealização de certos gêneros literários. Hoje em dia, diante de um poeta contemporâneo, essa é uma consideração menos válida, pois é mais possível que um poeta de hoje venha a escrever um soneto no mínimo em um molde de tradição do que venha a escrever um poema que desrealize o soneto.

Não somente resistente ao tempo, no sentido de resistir a mudanças de valores e da ordem regente do poder (político, econômico, legislativo, jurídico e de ofícios), pois o soneto não é uma entidade nem uma espécie natural, ele parece em seus quase oitocentos anos coadunar-se muito bem ao gosto, tanto da prática quanto do estudo e da fruição poética. No entanto, o soneto atravessa os séculos por outras razões que merecem crédito. $\mathrm{O}$ soneto foi produzido em uma corte decorrente de uma articulação imperial que influiu e ainda influi, o Império Romano-Germânico, pois Roma foi o império de controle ideológico do imaginário que incide na cultura literária, o território germânico esteve diretamente implicado na queda do Império Romano, Itália e Alemanha engendraram dois grandes períodos da formação estética ocidental, O Renascimento e o Romantismo - à parte toda a relação intrínseca que a Alemanha teve com a formação do Barraco -, assim como Itália e Alemanha não somente integraram dois terços da Tríade Aliança durante a Segunda Guerra Mundial, como também foram duas nações responsáveis, respectivamente, por um dos mais terríveis e pelo mais terrível regime de exceção da recente História Moderna do Ocidente, o fascismo e o nazismo. O soneto foi tratado pela muito influente Arte Poética (de 1674), de Boileau-Despreaux, como a excelência da poesia, a ponto de ser comparado, ainda que in abstracto, ou melhor, in virtua, com a tragédia e a epopeia - a afirmação é famosa: "un sonnet sans défaut vaut seul un long poème" (um soneto bem feito equivale a um poema longo". Os nomes mais canônicos da poesia 
ocidental do século XIII aos fins do XVII foram sonetistas, ainda que não tenham todos sidos canonizados por esse motivo - a saber: Dante, Petrarca, Boccaccio, Shakespeare e Cervantes. Depois do Romantismo, o soneto serviu como principal gênero da poesia ocidental da ordem parnasiana e simbolista, as quais, de resto, atuaram diretamente na formação do Modernismo - aquela tanto porque já não respondia às necessidades variantes nem às derivas do sensível quanto porque integra a formação da poesia como forma do pensamento abstrato, e esta porque seu princípio decadentista e seu gosto místico por uma percepção sugestiva de mundo incidiu profundamente no Modernismo.

É razoável compreender o curso valorativo do soneto ao longo de seus quase oitocentos anos muito mais por essas razões que têm base no princípio ideológico da formação dos gêneros literários do que entendê-lo como uma espécie de excelência em si, algo que por natureza. Além disso, como se defendeu do início ao fim deste artigo, o soneto é uma forma fixa e tais formas são variáveis. No ocidente, juntamente com o rondó, o soneto é a forma fixa de maior rigor formal, pois gazel, terça rima, canção, balada, vilancete e outras não têm extensão mínima nem máxima. E, ainda que divida essa cena com o rondó, esse basicamente deixou de ser praticado desde os fins do primeiro terço do século XVIII - ele não pareceu ao gosto dos neoclássicos nem dos árcades, assim como já não estava no gosto dos barrocos, e não está no gosto tem implicação direta com a propagação que o gênero recebe, ou seja, com a relação que a política de controle das Letras exerce para autenticar formas de expressão do sensível. Para que se tenha uma ideia disso, no Brasil o caso mais canônico decorre de uma retomada modernista, trata-se do "Rondó dos cavalinhos", de Manuel Bandeira, originalmente publicado em Estrela da manhã (de 1936). De certo modo, isso inclusive reforça o que falamos sobre Bandeira a respeito de frequentar assiduamente formas da tradição a 
ponto de desrealizá-las, como no caso de "O martelo", segundo a argumentação apresentada.

Ainda hoje o soneto não somente é largamente conhecido e reconhecido, como também é praticado por poetas que alcançam respaldo de público e de crítica especializada. É o caso da obra poética de Paulo Henriques Britto e de Glauco Mattoso. De Liturgia da matéria (de 1982) a Formas do nada (de 2012), Paulo Henriques pratica recursivamente o soneto, e se destaca como poeta do soneto simétrico (dístico-terceto-quarteto-terceto-dístico), tipo anterior ao século XVIII, infrequente e de origem desconhecida. A versatilidade de Paulo Henriques na prática dessa forma fixa é tal que pode-se dizer que este poeta possui hoje uma sonetologia: além do simétrico e do italiano, pratica soneto inglês, blocado e, inclusive, idílio em forma de soneto. Já Glauco Mattoso (Pedro José Ferreira da Silva), pelo menos a partir de 1999, quando publica Centopeia: sonetos nojentos \& quejandos, torna-se basicamente um sonetista, muito embora sua prática quase que se resuma ao molde italiano e variações - chama a atenção pelo senso crítico, pelo despojamento da linguagem e por recorrer a meneios de escrita do português antigo.

\section{Referências}

ANDRADE, Carlos Drummond de. Oficina irritada. In: . Obra

Completa. 2. ed. Rio de Janeiro: José Aguilar Editora, 1967. p. 245.

BANDEIRA, Manuel. O martelo. In: . Lira dos cinquent'anos. São Paulo: Global, 2013. p. 25.

BILAC. Olavo. A um poeta. In: . Obra reunida (org. Alexei Bueno). Rio de Janeiro: Nova Aguilar, 1996, p. 267.

BURT, Stephen; MIKICS, David (orgs.). The art fo sonnet. Cambridge: Havard UP, 2011. 
CAMPOS, Geir. Pequeno dicionário de arte poética. 3. ed. São Paulo: Cultrix, 1978.

LIMA, Renira Lisboa de Moura. A forma soneto. Maceió: Edufal, 2007.

MORAES, Vinícius de. Epitáfio. In: . Poemas, sonetos e baladas. São

Paulo: Gaveta, 1946. s/p.

PAGLIARO, A.; BAUSANI, A. Pagliaro e A. Bausani: Storia delle letteratura del persiana (1960) Inder Jit Lall: "Ghazal as a Form of Poetry and Music", Indian and Foreign Review, 1, 14 (1980). 